\title{
Contribución para el perfeccionamiento del diseño, la construcción y la operación de reactores UASB aplicados al tratamiento de aguas residuales urbanas - Parte 1: Temas de interés
}

\author{
Contribution for improving the design, construction and operation "Fecha de entrada: \\ of UASB reactors treating sewage - Part 1: Topics of Interest $\quad$ Fecha de aprobación. \\ $17 / 09 / 2018$
}

Carlos Augusto de Lemos Chernicharo (*) / Thiago Bressani Ribeiro / Eduardo Sabino Pegorini / Gustavo Rafael Collere Possetti / Marcelo Kenji Miki / Saulo Nonato de Souza

DOI: $10.4322 /$ dae.2018.038es

\section{Resumen}

Brasil posee el mayor parque de reactores anaerobios del mundo si se considera la aplicación de esta tecnología para el tratamiento de las aguas residuales urbanas. A pesar de las reconocidas ventajas de los reactores de tipo UASB, algunos problemas han impedido su máximo desempeño operacional. Ignorar la existencia y postergar la solución de esos desafíos puede poner en riesgo los importantes avances alcanzados hasta la fecha, impactando el futuro de la tecnología anaerobia en el país y, en consecuencia, el del sector nacional de saneamiento en aguas residuales. Esta Nota Técnica (NT) tiene por objetivo presentar los principales temas de interés relacionados a la necesidad de perfeccionamiento del diseño, la construcción y la operación de reactores UASB, a partir de un amplio levantamiento junto a especialistas del sectoracadémico y prestadores de servicios de saneamiento de Brasil. Los temas identificados fueron relacionados a los problemas más propensos a ocurrir en los reactores UASB, así como a sus respectivos orígenes. Para cada tema y problemas identificados, se indicaron las principales soluciones que han sido adoptadas, derivadas a partir de las investigaciones más recientes y de las experiencias exitosas en Plantas de Tratamiento de Aguas Residuales (PTARs) de Brasil. Los temas de interés se sintetizan en esta NTy son detallados en el conjunto de NTs que conforman la Colección "Contribución para el perfeccionamiento del diseño, la construcción y la operación de reactores UASB aplicados al tratamiento de aguas residuales urbanas”. Palabras clave: Biogás, calidad del efluente, corrosión, lodo, nata, olor, reactores anaerobios

\footnotetext{
Carlos Augusto de Lemos Chernicharo - Ingeniero Civil de la Universidad Federal de Minas Gerais (UFMG), Brasil. Doctor en Ingeniería Ambiental de la Universidad de Newcastle upon Tyne, UK. Profesor titular del Departamento de Ingeniería Sanitaria y Ambiental de la UFMG, Brasil. Coordinador del Instituto Nacional de Ciencia y Tecnología en Plantas Sostenibles de Tratamiento de Aguas Residuales Urbanas (INCT ETEs Sustentáveis por sus siglas en portugués).

Thiago Bressani Ribeiro - Ingeniero Ambiental de la Universidad Fundación Minera de Educación y Cultura (FUMEC), Brasil. Máster en Saneamiento, Medio Ambiente y Recursos Hídricos de la UFMG, Brasil. Doctorando en Saneamiento de la Universidad de Ghent, Bélgica y de la UFMG, Brasil. Miembro del Instituto Nacional de Ciencia y Tecnología en Plantas Sostenibles de Tratamiento de Aguas Residuales Urbanas (INCT ETEs Sustentáveis por sus siglas en portugués).

Eduardo Sabino Pegorini - Ingeniero Agrónomo de la Universidad del Paraná (UFPR), Brasil. Máster en Ciencias del Suelo de la UFPR, Brasil. Ingeniero de la Unidad de Proyecto KFW en la Compañía de Saneamiento de Paraná (Sanepar), Brasil.

Gustavo Rafael Collere Possetti - Ingeniero Ambiental e Ingeniero Electrictista de la Universidad Tecnológica Federal del Paraná (UTFPR), Brasil. Máster y Doctor en Ciencias de la UTFPR, Brasil. Gerente de la Asesoría de Investigación y Desarrollo de la Compañía de Saneamiento del Paraná (Sanepar). Profesor del programa de Maestría Profesional en Gobernanza y Sostenibilidad del Instituto Superior de Administración y Economía (ISAE). Miembro del Instituto Nacional de Ciencia y Tecnología en Plantas Sostenibles de Tratamiento de Aguas Residuales Urbanas (INCT ETEs Sustentáveis por sus siglas en portugués). Marcelo Kenji Miki-Ingeniero Civil y Máster de la Escuela Politécnica de la Universidad Federal de São Paulo (USP), Brasil. Gerente del Departamento de Ejecución de Proyectos de Investigación, Desarrollo e Innovación de la Compañía de Saneamiento del Estado de Sao Paulo (Sabesp), Brasil.

Saulo Nonato de Souza - Ingeniero Civil de la Universidad Federal de Minas Gerais (UFMG), Brasil. Ingeniero de Operación de la Compañía de Saneamiento de Minas Gerais (COPASA), Brasil. Estudiante de Maestría en Saneamiento, Medio Ambiente y Recursos Hídricos de la UFMG, Brasil

(*) Dirección para correspondencia: Avenida Antônio Carlos 6.627 - Universidade Federal de Minas Gerais - Escola de Engenharia - Departamento de Engenharia Sanitária e Ambiental - Bloco 1. Belo Horizonte, MG. CEP: 31270-901. e-mail: calemosadesa.ufmg.br
} 


\section{Abstract}

Brazil has the largest park of anaerobic reactors in the world, considering the technology application for sewage treatment. Despite the recognized advantages of UASB reactors, there are problems that have prevented their maximum operational performance. Neglecting the existence and delaying the solution of these challenges can jeopardize the important advances made to date, impacting the future of anaerobic technology in the country and, consequently, the national sewage sector. This Technical Note (TN) aims to present the main topics of interest related to the need for improvements in the design, construction and operation of UASB reactors, based on a wide survey with experts from the academic sector and national sanitation service providers. The identified topics were correlated to the problems likely to occur in UASB reactors, as well as to their respective origins. For each topic and identified problems, indications were given of the main solutions that have been adopted, in view of the most recent researches and successful experiences in Sewage Treatment Plants in Brazil. The topics of interest are summarily reported in this $T N$, and are further detailed in the set of Technical Notes that integrate the Collection "Contribution for improving the design, construction and operation of UASB reactors treating sewage". Keywords: Anaerobic reactors, biogas, corrosion, effluent quality, odour, scum, sludge

\section{INTRODUÇÃO}

A partir de la experiencia con filtros anaerobios reportada en el artículo clásico de Young \& McCarty (1969), un grupo de investigadores de la Universidad de Wageningen (Holanda), liderado por el profesor Gatze Lettinga, sugirió substituir el medio de soporte por un separador de fases (líquida, sólida y gaseosa) en la parte superior del reactor. Ese aspecto se configuró en el inicio del desarrollo de los reactores anaerobios de manto de lodo y flujo ascendente (UASB, por sus siglas del inglés Upflow Anaerobic Sludge Blanket) (LETTINGA, 2014). Las primeras investigaciones con los reactores UASB se asociaron al tratamiento de efluentes industriales del procesamiento de papas para la extracción de almidón y el procesamiento de remolacha para la obtención de azúcar. A mediados de la década de 1970, se realizaron las primeras pruebas con reactores UASB en escala de laboratorio $(30-120 \mathrm{~L})$ y piloto $\left(6 \mathrm{~m}^{3}\right)$ tratando aguas residuales urbanas de la comunidad de Bennekom (Holanda). No obstante, problemas asociados a la necesidad de calentar el agua residual, procurando simular las temperaturas de los países de clima tropical, motivaron la búsqueda de convenios para la implantación de reactores UASB en países en desarrollo. A partir de esto, un proyecto entre los gobiernos holandés y colombiano, con la participación de la Universidad de Wageningen y de la empresa consultora Royal Haskoning, posibilitó la implantación de un reactor UASB en escala de demostración $\left(64 \mathrm{~m}^{3}\right)$ en la ciudad de Cali
(LETTINGA, 2014). Los buenos resultados asociados al proyecto de investigación fomentaron la definición de bases iniciales para los criterios de diseño, operación y mantenimiento de reactores UASB aplicados al tratamiento de aguas residuales urbanas. A partir de esa experiencia, entre las décadas de 1980 y 1990 se implantaron reactores en escala plena $\left(\sim 1.000 \mathrm{~m}^{3}\right)$ en la propia ciudad de Cali, así como proyectos de investigación en India, Gana, Medio Oriente y América Latina, particularmente en Brasil, Colombia y México.

Específicamente en Brasil, el uso de reactores UASB para el tratamiento de aguas residuales urbanas fue introducido durante la década de 1980, cuando se iniciaron proyectos de varios grupos de investigación nacionales y de ingenieros actuantes en el sector. Específicamente en el estado de Paraná, debe mencionarse que los diseñadores de la Compañía de Saneamiento de Paraná (Sanepar) estuvieron en Holanda durante la década de 1980, lo que les permitió interactuar con el profesor Gatze Lettinga. De esa interacción resultó la concepción de los reactores anaerobios de lecho fluidizado (RALF), una variante del reactor UASB ampliamente usado por la Sanepar. Durante sus etapas iniciales, el diseño y la operación todavía incipientes de los reactores UASB crearon barreras a la credibilidad del sistema, culminando con el rechazo de la tecnología anaerobia por parte de algunos prestadores de servicios de saneamiento y órganos ambientales. Sin embargo, la confianza ha venido siendo restablecida en las décadas recientes como resultado 
de la intensificación de estudios e investigaciones en el área, así como a partir de la experiencia obtenida con la operación de reactores en escala plena. Sin duda alguna, una importante contribución para la consolidación y la diseminación de la tecnología anaerobia para el tratamiento de las aguas residuales en Brasil se debe al Programa de Investigaciones en Saneamiento Básico (PROSAB, por sus siglas en portugués), desarrollado en Brasil entre los años 1997 y 2007 (CAMPOS, 1999; CHERNICHARO, 2001).

Es un hecho que las plantas de tratamiento de aguas residuales (PTARs) compuestas por reactores UASB seguidos de un postratamiento aerobio permiten, de manera general, una reducción de los costos de implantación (CAPEX) de entre $20-50 \%$ y de operación (OPEX) superior a 50\%, cuando son comparadas con PTARs convencionales de lodos activados (SILVA, 1993; ALEM SOBRINHO \& JORDÃO, 2001; von SPERLING \& CHERNICHARO, 2005; CHERNICHARO, 2006). Esa es una de las razones detrás del incremento de los niveles del tratamiento de las aguas residuales en América Latina (CHERNICHARO et al., 2015). En Brasil, los reactores UASB son actualmente la principal tendencia tecnológica para el tratamiento de aguas residuales urbanas, ya sea como unidades únicas, o bien seguidas de alguna forma de postratamiento. Según el levantamiento realizado por Chernicharo et al. (2018), cerca del $40 \%$ de las PTARs localizadas en las regiones Sur, Sudeste y Centro-Oeste de Brasil utilizan reactores UASB en su proceso de tratamiento. Esto permite afirmar que este país posee el mayor parque de reactores anaerobios del mundo, cuando se considera su aplicación para el tratamiento de las aguas residuales urbanas.

Además de la simplicidad operacional de los reactores UASB cuando se comparan a los procesos aerobios convencionales (lodo activado) o físico-químicos, y aparte de los aspectos financieros mencionados anteriormente, la concentración de la biomasa $\left(2-6 \mathrm{~g} \cdot \mathrm{L}^{-1}\right)$ y la edad del lodo (> 30 días) en el reactor son típicamente elevadas, lo que reduce significativamente su volumen en relación a otros procesos de tratamiento de efluentes. Otras ventajas de los reactores UASB son la ausencia de un medio de soporte, debido al crecimiento disperso de la biomasa, la baja producción de lodo y el reducido consumo energético, típicos de los sistemas anaerobios. Adicionalmente, el lodo excedente a ser descartado ya se encuentra espesado y digerido, siendo posible enviarlo directamente a la unidad de deshidratación. Finalmente, se destaca la posibilidad asociada a la generación y colecta del biogás, el cual es aprovechable energéticamente debido a su composición rica en metano. De acuerdo a resultados recientes del Proyecto Brasil-Alemania de Fomento al Aprovechamiento Energético de Biogás en Brasil (PROBIOGÁS), el contenido promedio de metano en el biogás proveniente de reactores UASB tratando aguas residuales urbanas varía entre 70 y $81 \%$ (BRASIL, 2017), lo que corresponde a un poder calorífico de aproximadamente $10 \mathrm{kWh} . \mathrm{Nm}^{-3}$ (MORAN et al., 2010).

A pesar de estas reconocidas ventajas, el uso de reactores UASB en Brasil todavía presenta desafíos que impiden su máximo desempeño operacional. Parte importante de los problemas asociados a estos reactores anaerobios se origina en deficiencias durante las fases iniciales del diseño. Sin embargo, procesos constructivos inadecuados y problemas operacionales también han sido reportados por la literatura y por los prestadores de servicios de saneamiento en diversas regiones del Brasil (MIKI, 2010). Aparte de los problemas técnicos de diseño, construcción y operación, en ocasiones los problemas operacionales se producen por situaciones que escapan al control de las PTARs, como en el caso de problemas en la gestión de los sistemas, esto se refleja en fallas administrativas y financieras, que con frecuencia impiden la ejecución adecuada de procedimientos operacionales esenciales. Por lo tanto, ignorar su existencia y postergar la solución de estos problemas puede poner en riesgo los importantes avances conseguidos hasta la fecha, impactando el futuro de la tecnología anaerobia en Brasil. Esto constituiría un impacto sin precedentes para el sector nacional del tratamiento de aguas residuales, con riesgos enormes de incidir directamente en el estancamiento de los índices de cobertura del tratamiento de las aguas residuales en Brasil. 
Es importante destacar que la mayoría de los problemas abordados en esta Colección de Notas Técnicas puede ser corregida de manera simple y efectiva, sin impactos significativos sobre los costos de los reactores, con la condición de que se dedique más atención a las etapas de diseño y de construcción, así como a una mejor capacitación de los operadores de las plantas de tratamiento. Muy probablemente, los problemas de administración están asociados a la mayoría de las PTARs, independientemente de la tecnología de tratamiento utilizada. Se cree, por lo tanto, que las informaciones contenidas en este conjunto de Notas Técnicas pueden contribuir decisivamente para la corrección de casi la totalidad de los problemas de diseño, construcción y operación de reactores UASB.

\section{CONSOLIDACIÓN DE LOS TEMAS DE INTERÉS}

Los principales temas de interés relacionados a la necesidad de perfeccionamiento del diseño, la construcción y la operación de reactores UASB están representados esquemáticamente en la Figura 1, como resultado de un amplio levantamiento realizado junto a especialistas del sector académico y de prestadores nacionales de servicios de saneamiento.

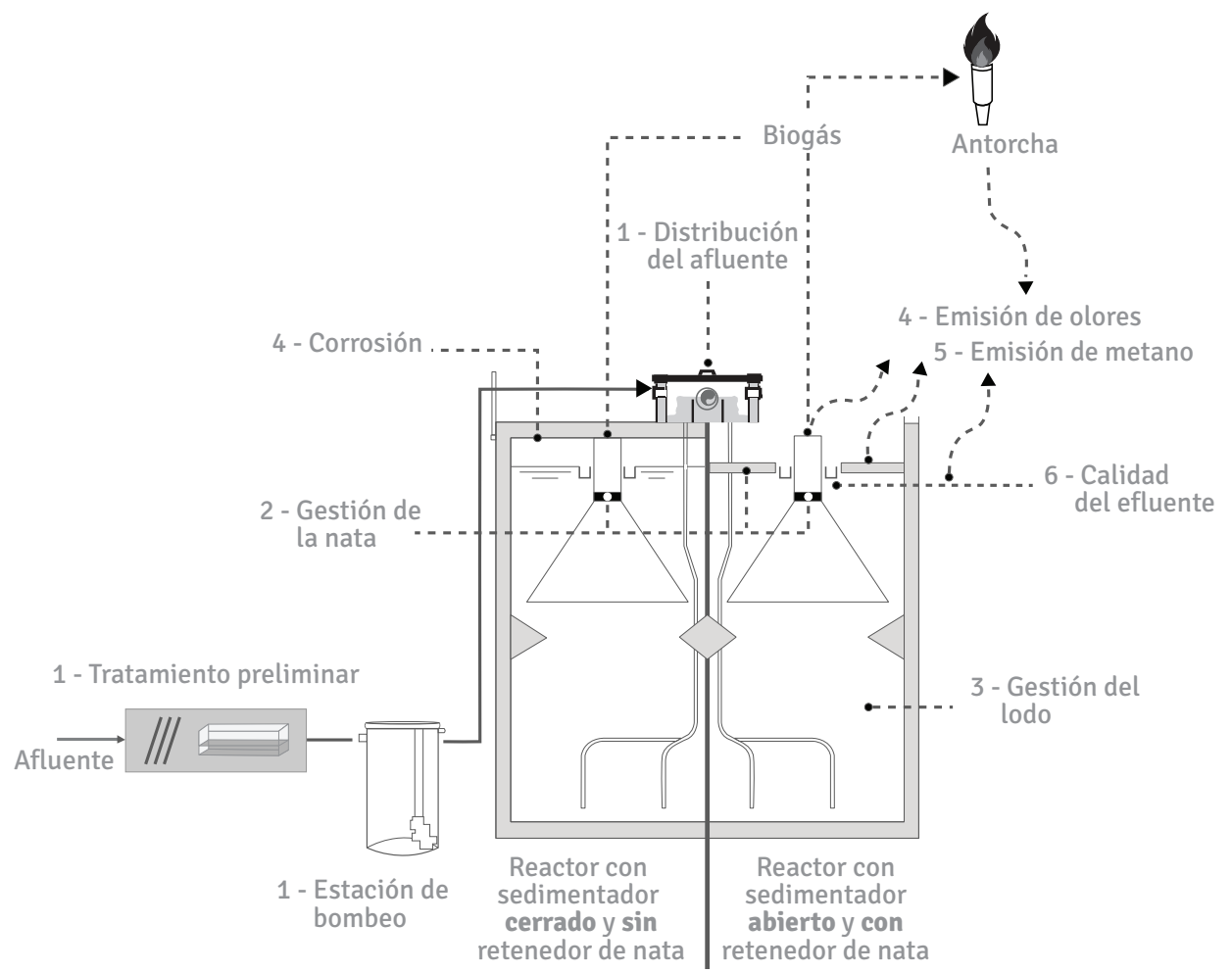

Figura 1 - Temas de interés para el perfeccionamiento de los reactores UASB

Los temas de interés identificados se describen de forma sintética en la presente Nota Técnica (NT) y se detallan, según se muestra en el Cuadro 1, en las NTs complementarias que integran la colección "Contribución para el perfeccionamiento del diseño, la construcción y la operación de reactores UASB aplicados al tratamiento de aguas residuales urbanas".
En el Cuadro 2, estos temas de interés fueron relacionados a los problemas susceptibles de ocurrir en reactores UASB, así como a sus respectivos orígenes, según las experiencias de PTARs en Brasil. Como elemento final del Cuadro 2 se indican las principales soluciones que han sido adoptadas en el Brasil para la solución de los problemas descritos. 
Cuadro 1: Relación entre los principales temas de interés para el perfeccionamiento de los reactores UASB y Notas Técnicas correspondientes

\begin{tabular}{|c|c|}
\hline Temas de interés & Nota Técnica correspondiente \\
\hline $\begin{array}{l}\text { Tratamiento preliminar, bombeoy } \\
\text { distribución de caudal }\end{array}$ & $\begin{array}{l}\text { Parte 2: Tratamiento preliminar, bombeo y distribución de } \\
\text { caudal (BRESSANI-RIBEIRO et al., 2018). }\end{array}$ \\
\hline 2. Gestión de la nata & \multirow{2}{*}{ Parte 3: Gestión del lodo y la nata (LOBATO et al., 2018). } \\
\hline 3. Gestión del lodo & \\
\hline 4. Corrosión y emisiones odorantes & $\begin{array}{l}\text { Parte 4: Control de corrosión y emisiones odorantes } \\
\text { (BRANDT et al., 2018). }\end{array}$ \\
\hline 5. Biogás y emisiones fugitivas de metano & $\begin{array}{l}\text { Parte 5: Biogás y emisiones fugitivas de metano } \\
\text { (POSSETTI et al., 2018). }\end{array}$ \\
\hline 6. Calidad del efluente & Parte 6: Calidad del efluente (ALMEIDA et al., 2018). \\
\hline
\end{tabular}

\section{Cuadro 2: Principales temas de interés para el perfeccionamiento del diseño, la construcción y la operación de} reactores UASB

\begin{tabular}{|c|c|c|c|}
\hline Temas de interés & Problemas asociados & Origen del problema & Posibles mejoras \\
\hline & $\begin{array}{l}\text {-Ocurrencia de olores en las } \\
\text { inmediaciones del tratamiento } \\
\text { preliminar (TP); } \\
\text { - Formación de depósitos de } \\
\text { arena en los canales del TP; } \\
\text {-Empozamiento de lixiviados } \\
\text { en los contenedores de } \\
\text { residuos removidos en el TP. }\end{array}$ & $\begin{array}{l}\text { - Existencia de puntos de turbulencia en las unidades } \\
\text { del TP que favorecen la liberación de sulfuro de } \\
\text { hidrógeno disuelto en la fase líquida (agua residual } \\
\text { afluente a la PTAR); } \\
\text { - Los sólidos removidos en el TP contienen materia } \\
\text { orgánica, la cual puede entrar en descomposición } \\
\text { y generar malos olores durante el período de } \\
\text { almacenamiento de los contenedores utilizados para } \\
\text { la acumulación de esos residuos; } \\
\text { - Alteraciones de la sección transversal de los } \\
\text { canales, ocasionando la disminución de las } \\
\text { velocidades del flujo hidráulico y la consecuente } \\
\text { deposición de sólidos de naturaleza orgánica; } \\
\text { - Velocidades inferiores a las mínimas previstas en el } \\
\text { diseño durante el inicio de operación de la PTAR; } \\
\text { - Ausencia de contención y drenaje de las áreas } \\
\text { en las que se colocan los contenedores para el } \\
\text { almacenamiento de los residuos del TP. }\end{array}$ & $\begin{array}{l}\text { - Implantar el confinamiento, extracción y } \\
\text { tratamiento de los gases procedentes de las } \\
\text { áreas con mayor turbulencia y emisiones de gases } \\
\text { disueltos (ver detalles en la Parte } 4 \text { de esta Colección } \\
\text { de NTs - BRANDT et al., 2018); } \\
\text { - Lanzar cal sobre los residuos en el contenedor para } \\
\text { neutralizar la emisión de olores; } \\
\text { - Reducir el tiempo de almacenamiento del } \\
\text { contenedor en la PTAR; } \\
\text { - Evaluar alternativas de modulación para la } \\
\text { implantación del TP, con el fin de mantener } \\
\text { velocidades mínimas de flujo hidráulico, } \\
\text { especialmente al inicio de la operación del sistema; } \\
\text { - Utilizar áreas específicas para colocar los } \\
\text { contenedores con contención y drenajes de los } \\
\text { líquidos, que deben ser devueltos para el TP. } \\
\text { Adicionalmente, prever el techado de esas áreas para } \\
\text { evitar/reducir el aporte de agua de lluvia. }\end{array}$ \\
\hline $\begin{array}{l}1 \text { - Tratamiento } \\
\text { preliminar, bombeo y } \\
\text { distribución de caudal }\end{array}$ & $\begin{array}{l}\text { - Caudales de bombeo no } \\
\text { compatibles con los caudales } \\
\text { promedio y máximo utilizados } \\
\text { para el diseño de los reactores } \\
\text { anaerobios; } \\
\text { - Inundación de rejillas } \\
\text { implantadas aguas arriba de } \\
\text { las estaciones de bombeo; } \\
\text { - Ausencia de control de la } \\
\text { frecuencia y de los caudales } \\
\text { que producen rebalses en la } \\
\text { PTAR. }\end{array}$ & $\begin{array}{l}\text { - Muchas estaciones de bombeo de aguas residuales } \\
\text { (EBAR) de pequeña y mediana escala son diseñados } \\
\text { con apenas dos bombas, siendo una para relevo y } \\
\text { respaldo. En esas situaciones, el caudal nominal de } \\
\text { cada bomba debe ser mayor o igual al caudal máximo } \\
\text { de diseño de los reactores UASB; } \\
\text { - A su vez, el dimensionamiento hidráulico de los } \\
\text { reactores es realizado en base al caudal promedio de } \\
\text { diseño, calculando y verificando el funcionamiento } \\
\text { del sistema para una condición de caudal máximo } \\
\text { (usando los coeficientes de caudal máximo diario y } \\
\text { de caudal máximo horario), y limitando la operación } \\
\text { del reactor en esa condición extrema a un período } \\
\text { no mayor de } 2 \text { - } 4 \text { horas. Es decir, las EBARs que } \\
\text { operan con apenas una bomba yue no disponen de } \\
\text { variadores de frecuencia estarán bombeando siempre, } \\
\text { un caudal igual o superior al caudal máximo de diseño } \\
\text { de los reactores UASB, exponiéndolos a condiciones de } \\
\text { sobrecarga hidráulica durante el bombeo; } \\
\text { - Ante lo expuesto anteriormente, el hidrograma de } \\
\text { caudales afluentes al reactor UASB es diferente al } \\
\text { hidrograma de caudales afluentes a la PTAR; } \\
\text { - El dispositivo de control de caudal pico (rebalse o } \\
\text { vertedero) es comúnmente implantado junto a la } \\
\text { pared lateral del canal de llegada al TP. Sin embargo, } \\
\text { en PTARs en las que la EBAR de llegada está localizada } \\
\text { aguas abajo del TPy, en las que existe riesgo de } \\
\text { interrupción en la alimentación de la energía eléctrica, } \\
\text { puede ocurrir la inundación de las unidades del TP } \\
\text { localizadas aguas arriba de la EBAR, cuando esta } \\
\text { unidad no posee un rebalse propio e independiente } \\
\text { del TP; } \\
\text { - Las PTARs usualmente no disponen de un registro } \\
\text { de eventos de rebalse y control de caudales excesivos } \\
\text { que son descargados directamente en el cuerpo de } \\
\text { agua receptor. }\end{array}$ & $\begin{array}{l}\text { - Utilizar bombas con variadores de velocidad } \\
\text { (variadores de frecuencia) o instalar al menos tres } \\
\text { bombas, siendo una para relevo y respaldo, tal como } \\
\text { recomienda la norma brasileña (NBR) } 12.209 \text { en el } \\
\text { inciso } 6.4 .2 \text { (ABNT, 2011); } \\
\text { - Instalar un medidor de caudal en la descarga de } \\
\text { la estación de bombeo, con el fin de verificar los } \\
\text { caudales realmente enviados hacia el reactor UASB, } \\
\text { especialmente cuando las bombas operen sin } \\
\text { variadores de frecuencia. En este caso, sería posible } \\
\text { obtener el hidrograma de caudal afluente al reactor } \\
\text { UASB; } \\
\text { - Colocar rebalses para los excedentes de caudal que } \\
\text { protejan efectivamente de sobrecargas hidráulicas } \\
\text { a las unidades aguas abajo. En este caso, dos } \\
\text { rebalses de excedencia, uno antes del TPy otro } \\
\text { asociado al pozo húmedo de la EBAR de llegada son } \\
\text { necesarios para evitar la inundación de las unidades } \\
\text { implantadas aguas arriba de la estación de bombeo; } \\
\text { - Instalar medidores de caudal en el canal de } \\
\text { excedentes de la PTAR, con el fin de asegurar el } \\
\text { registro de la frecuencia y magnitud de los caudales } \\
\text { afluentes derivados para el cuerpo receptor. }\end{array}$ \\
\hline
\end{tabular}




\begin{tabular}{|c|c|c|c|}
\hline Temas de interés & Problemas asociados & Origen del problema & Posibles mejoras \\
\hline \multirow{2}{*}{$\begin{array}{l}1 \text { - Tratamiento } \\
\text { preliminar, bombeo y } \\
\text { distribución de caudal }\end{array}$} & $\begin{array}{l}\text { - Distribución no uniforme del caudal en los } \\
\text { tubos de alimentación de reactor, pudiendo } \\
\text { ocasionar dentro del reactor: } \\
\text { - acumulación de sólidos en los puntos en } \\
\text { los que ocurre el estancamiento del agua } \\
\text { residual; } \\
\text { - formación de zonas muertas y consecuente } \\
\text { levantamiento de lodo excesivo en los } \\
\text { puntos no alimentados; } \\
\text { - formación de flujos preferenciales en las } \\
\text { zonas que reciben alimentación excesiva; } \\
\text { - eventualmente, puede haber una caída } \\
\text { en la eficiencia de retención de sólidos y de } \\
\text { remoción de materia orgánica. }\end{array}$ & 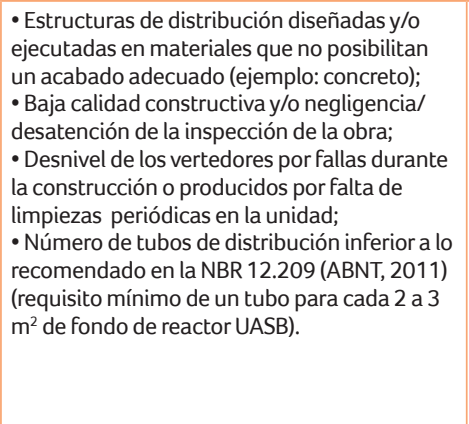 & $\begin{array}{l}\text { - Utilizar cajas de distribución confeccionadas en } \\
\text { materiales que posibiliten un mejor acabado (ejemplo: } \\
\text { fibra de vidrio y polipropileno); } \\
\text { - Incluir cajas de recepción y distribución de lodo } \\
\text { aerobio de descarte, de modo que permitan la } \\
\text { flexibilidad de maniobra durante la alimentación de } \\
\text { ese lodo de descarte entre los distintos módulos de } \\
\text { los reactores UASB; } \\
\text { - Rigurosidad del equipo de inspección durante el } \\
\text { seguimiento de la obra; } \\
\text { - Verificar el nivel de los vertedores durante la } \\
\text { recepción de la obra y periódicamente después del } \\
\text { inicio de la operación. Realizar también limpiezas } \\
\text { periódicas de los vertedores, evitando su obstrucción } \\
\text { parcial. }\end{array}$ \\
\hline & $\begin{array}{l}\text { - Obstrucción frecuente de los tubos de } \\
\text { alimentación del reactor UASB, aumentando } \\
\text { el trabajo del operador con la desobstrucción } \\
\text { de los mismos; } \\
\text { - Fijación inadecuada de los tubos de } \\
\text { distribución junto a la caja de distribución y } \\
\text { en el fondo del reactor; } \\
\text { - Acumulación de arenay sólidos en los } \\
\text { compartimientos de distribución. }\end{array}$ & $\begin{array}{l}\text { - Elevada presencia de sólidos (desechos) en } \\
\text { el agua residual, como consecuencia de los } \\
\text { malos usos de las instalaciones sanitarias y del } \\
\text { sistema de alcantarillado como un todo; } \\
\text { - Unidades del tratamiento preliminar } \\
\text { diseñadas o ejecutadas en no conformidad } \\
\text { con la norma NBR } 12.209 \text { (ABNT, 2011); } \\
\text { - Unidades del tratamiento preliminar } \\
\text { fuera de operación por cuestiones de } \\
\text { mantenimiento; } \\
\text { - Compartimientos de distribución diseñados } \\
\text { con fondo plano y/o baja inclinación; } \\
\text { - Tubos de alimentación del reactor con } \\
\text { diámetro inferior al recomendado por la } \\
\text { norma NBR 12.209 y/o con longitud excesiva } \\
\text { y/o con cambios de dirección que dificultan el } \\
\text { libre paso del agua residual (ABNT, 2011). }\end{array}$ & $\begin{array}{l}\text { - Realizar campañas de sensibilización de los usuarios } \\
\text { yusuarias del sistema del alcantarillado sanitario, con } \\
\text { el fin de reducir el lanzamiento de desechos sólidos } \\
\text { en la red; } \\
\text { - Utilizar unidades de tratamiento preliminar (rejillas, } \\
\text { tamices y desarenadores) de comprobada eficienciay } \\
\text { que cumplan con las prescripciones de la norma NBR } \\
12.209 \text { (ABNT, 2011); } \\
\text { - Instalar estructuras de distribución de caudal } \\
\text { diseñadas con fondo inclinado, de modo que se } \\
\text { minimice la acumulación de arenay yólidos; } \\
\text { - Mejorar los diseños del tratamiento preliminar } \\
\text { para aumentar la confiabilidad, minimizar el } \\
\text { mantenimiento de los equipos y aumentar la } \\
\text { eficiencia (ver recomendaciones en la Parte } 2 \text { de esta } \\
\text { Colección de NTs - BRESSANI-RIBEIRO et al., 2018); } \\
\text { - Garantizar la rigurosidad del equipo de inspección } \\
\text { durante el acompañamiento de la obra e instalación } \\
\text { de los equipos; } \\
\text { - Adoptar rutinas y procedimientos de limpieza de las } \\
\text { cajas de distribución; } \\
\text { - Utilizar un dispositivo de desobstrucción de los } \\
\text { tubos de alimentación del reactor UASB. }\end{array}$ \\
\hline 2 - Gestión de la nata & $\begin{array}{l}\text { - Acumulación de una capa sólida y espesa } \\
\text { de nata (espuma densa) en la superficie } \\
\text { de los sedimentadores. Este material es } \\
\text { usualmente de difíili remoción y puede } \\
\text { ocasionar daños a las canaletas de } \\
\text { colecta del líquido y pérdida de calidad del } \\
\text { efluente del reactor; } \\
\text { - Acumulación de una capa superficial } \\
\text { sólida y espesa de nata en el interior de los } \\
\text { separadores trifásicos (STF). Este material } \\
\text { es de difícil remoción por parte del } \\
\text { operador de la PTAR, constituyendo, por } \\
\text { lo tanto, uno de los principales problemas } \\
\text { operacionales de los reactores UASB } \\
\text { implantados en Brasil; } \\
\text { - La capa de nata en el interior de los STF } \\
\text { tiende a impedir la liberación del biogás } \\
\text { producido en el reactor anaerobio y, al } \\
\text { mismo tiempo: } \\
\text { - Ocasionar el paso del biogás para el } \\
\text { compartimiento de sedimentación, con } \\
\text { impactos directos sobre la calidad del } \\
\text { efluente (pérdida de sólidos) y sobre los } \\
\text { niveles de emisión de gases odorantes y de } \\
\text { efecto invernadero; } \\
\text { - Reducir la recuperación de biogás para } \\
\text { fines de quema y/o aprovechamiento } \\
\text { energético; } \\
\text { - Reducir el volumen útil de la cámara de } \\
\text { gas y modificar su presión de operación. } \\
\text {-El espesamiento de la capa de nata } \\
\text { puede producir esfuerzos estructurales } \\
\text { elevados en las paredes del STF. Estos } \\
\text { esfuerzos pueden ocasionar daños y hasta } \\
\text { la ruptura del STF, principalmente cuando } \\
\text { éstos están confeccionados con materiales } \\
\text { de menor resistencia, como por ejemplo } \\
\text { lonas plásticas, láminas metálicas o de } \\
\text { asbesto etc. }\end{array}$ & $\begin{array}{l}\text { - La acumulación de nata en la superficie } \\
\text { de los sedimentadores y en el interior } \\
\text { de los STF de reactores UASB depende } \\
\text { de las características del agua residual } \\
\text { cruda, particularmente en relación a la } \\
\text { presencia de desechos sólidos (plástico, } \\
\text { hisopos, cabello, hilo dental etc.) y de } \\
\text { grasas y aceites. Parte de esos materiales, } \\
\text { principalmente los de menor densidad, } \\
\text { cuando no son adecuadamente removidos } \\
\text { en el tratamiento preliminar (rejillas y } \\
\text { tamices), tienden a fotar en el interior del } \\
\text { reactor y se acumulan en la parte superior } \\
\text { del STF, constituyendo la "nata"; } \\
\text { - Las características constructivas de los } \\
\text { reactores y las condiciones hidráulicas de } \\
\text { operación pueden producir que buena parte } \\
\text { de la nata esté formada por lodo flotante; } \\
\text { La ausencia de accesos adecuados y/o falta } \\
\text { de condiciones de seguridad ocupacional } \\
\text { para el procedimiento de descarte de la } \\
\text { nata; } \\
\text { - Ineficiencia del mecanismo de remoción } \\
\text { de nata del STFy/o no remoción frecuente y } \\
\text { sistemática de ese material fotante puede } \\
\text { llevar al espesamiento y solidificación de la } \\
\text { capa de nata. }\end{array}$ & $\begin{array}{l}\text { - Considerar mejoras en el tratamiento preliminar, de } \\
\text { modo que se reduzca la entrada de desechos sólidos, } \\
\text { sólidos flotantes y grasas y aceites en los reactores. } \\
\text { De entre los aspectos recomendados, puede } \\
\text { mencionarse la utilización de rejillas ultrafinas (6 } \\
\text { a } 10 \text { mm) y de tamices de pequeña abertura (3 a } \\
4 \text { mm) (ver recomendaciones en la Parte } 2 \text { de esta } \\
\text { Colección de NTs - BRESSANI-RIBEIRO et al., 2018); } \\
\text { - Controlar la recepción de descargas de efluentes } \\
\text { no domésticos (END) tales como lodo de tanque } \\
\text { séptico y efluentes de industrias con aceites y } \\
\text { grasas usualmente elevados (lecherías, mataderos, } \\
\text { sistemas frigoríficos, lavanderías industriales etc.); } \\
\text { - Utilizar STF equipados con dispositivos internos } \\
\text { que posibiliten la remoción de la nata, como por } \\
\text { ejemplo el Separador Etsus } 1000 \text { (ver detalles en } \\
\text { la Parte } 3 \text { de esta Colección de NTs - LOBATO et al., } \\
\text { 2018); } \\
\text { - Utilizar cámaras múltiples piramidales, de modo a } \\
\text { posibilitar el confinamiento de la nata en menores } \\
\text { áreas y así facilitar su remoción (ver detalles en la } \\
\text { Parte } 3 \text { de esta Colección de NTs - LOBATO et al., } \\
\text { 2018); } \\
\text { - Cuando no sea posible la utilización de dispositivos } \\
\text { internos de remoción de nata, la parte superior del } \\
\text { STF debe estar equipada con un número suficiente } \\
\text { de tapas de inspección, de modo a posibilitar } \\
\text { la efectiva remoción del material flotante. Sin } \\
\text { embargo, esta alternativa no es la ideal, pues resulta } \\
\text { en liberación de biogás a la atmósfera. Cuando se } \\
\text { utilice, debe tenerse especial cuidado en garantizar } \\
\text { la estanqueidad de la cámara de biogás y en tener } \\
\text { acceso adecuado para los equipos de remoción } \\
\text { de nata, manteniendo condiciones adecuadas de } \\
\text { seguridad ocupacional para los operadores; } \\
\text { - Considerar durante el diseño de las unidades de } \\
\text { tratamiento de la fase sólida de la PTAR la previsión } \\
\text { de carga de sólidos correspondiente a la nata } \\
\text { removida de los reactores anaerobios. }\end{array}$ \\
\hline
\end{tabular}




\begin{tabular}{|c|c|c|c|}
\hline Temas de interés & Problemas asociados & Origen del problema & Posibles mejoras \\
\hline 3 - Gestión del lodo & $\begin{array}{l}\text { - Gran parte de los reactores UASB } \\
\text { existentes en Brasil operan con exceso } \\
\text { de lodo, ocupando volúmenes mayores } \\
\text { a la capacidad de almacenamiento en } \\
\text { el compartimiento de digestión de los } \\
\text { reactores. Esto sucede, normalmente, } \\
\text { debido a la falta de descartes } \\
\text { sistemáticos de lodo y puede ocasionar: } \\
\text { - Paso excesivo de lodo desde el } \\
\text { compartimiento de digestión hacia el } \\
\text { compartimiento de sedimentación, } \\
\text { con el consecuente incremento de la } \\
\text { pérdida de sólidos en el efluente del } \\
\text { reactor; } \\
\text { - La pérdida de sólidos en el efluente } \\
\text { ocasiona la inmediata caída de la } \\
\text { eficiencia física de remoción de } \\
\text { materia orgánica del reactor, como } \\
\text { consecuencia del aumento de la parcela } \\
\text { de DQO y DBO particulada presente en } \\
\text { el efluente; } \\
\text { - Aumento de la formación de nata } \\
\text { en el interior del compartimiento de } \\
\text { sedimentación del reactor UASB; } \\
\text { - Acumulación excesiva de arena en el } \\
\text { fondo de los reactores; } \\
\text { - Disminución del volumen útil para el } \\
\text { tratamiento del agua residual; } \\
\text { - Sobrecarga y eventual } \\
\text { comprometimiento de la unidad de } \\
\text { postratamiento, particularmente para } \\
\text { aquellas que operan con algún medio } \\
\text { de soporte (por ejemplo: biofiltros y } \\
\text { filtros biológicos percoladores); } \\
\text { - Dificultades en la gestión del lodo } \\
\text { aerobio generado en la unidad de } \\
\text { postratamiento, cuando éste es } \\
\text { retornado para el espesamiento y } \\
\text { digestión en el reactor UASB; } \\
\text { - El arrastre de sólidos con el efluente } \\
\text { del reactor UASB puede alterar los } \\
\text { parámetros cinéticos utilizados para } \\
\text { el dimensionamiento de la unidad de } \\
\text { postratamiento. }\end{array}$ & $\begin{array}{l}\text { - La acumulación excesiva de lodo en } \\
\text { los reactores y la falta de descartes } \\
\text { sistemáticos están asociados a uno o más } \\
\text { de los siguientes factores: } \\
\text { - Manuales o directrices de operación } \\
\text { que no detallan adecuadamente los } \\
\text { procedimientos de descarte de lodo que } \\
\text { deben ser seguidos por los operadores; } \\
\text { - Lechos de secado y/o equipos de } \\
\text { deshidratación de lodo con capacidad } \\
\text { inferior a la requerida para el } \\
\text { procesamiento de la PTAR; } \\
\text { - Equipos del sistema de deshidratación } \\
\text { (bombas de lodo, dosificadoras de } \\
\text { polímero, centrífugas, entre otros) fuera } \\
\text { de operación, como consecuencia de } \\
\text { dificultades para dar mantenimiento } \\
\text { preventivo y correctivo a los mismos; } \\
\text { - Fallas en la instalación mecánica del } \\
\text { sistema de deshidratación, ocasionando } \\
\text { necesidad elevada de mantenimiento } \\
\text { correctivo; } \\
\text { - Falta de remoción sistemática de lodo } \\
\text { de los lechos de secado, impidiendo el } \\
\text { descarte del lodo del reactor; } \\
\text { - Falta de remoción sistemática de lodo de } \\
\text { los reactores UASB como consecuencia de } \\
\text { problemas logísticos/administrativos; } \\
\text { - Coeficiente de producción de lodo } \\
\text { superior al considerado en la fase } \\
\text { de diseño, como consecuencia de } \\
\text { la recepción en la PTAR de cargas } \\
\text { no consideradas originalmente (por } \\
\text { ejemplo: lodo de tanque séptico, lixiviado } \\
\text { de relleno sanitario, lodo químico de } \\
\text { plantas de agua potable y efluentes no } \\
\text { domésticos). } \\
\text { - La acumulación de arena en el fondo } \\
\text { de los reactores se debe, principalmente, } \\
\text { a problemas en el desarenador. Estos } \\
\text { problemas pueden estar relacionados con } \\
\text { deficiencias de diseño, de construcción } \\
\text { y/o de operación en esa unidad; } \\
\text { - Número insuficiente de tubos para } \\
\text { el descarte de lodos del reactor UASB } \\
\text { y/o tubos mal distribuidos a lo largo del } \\
\text { reactor. }\end{array}$ & 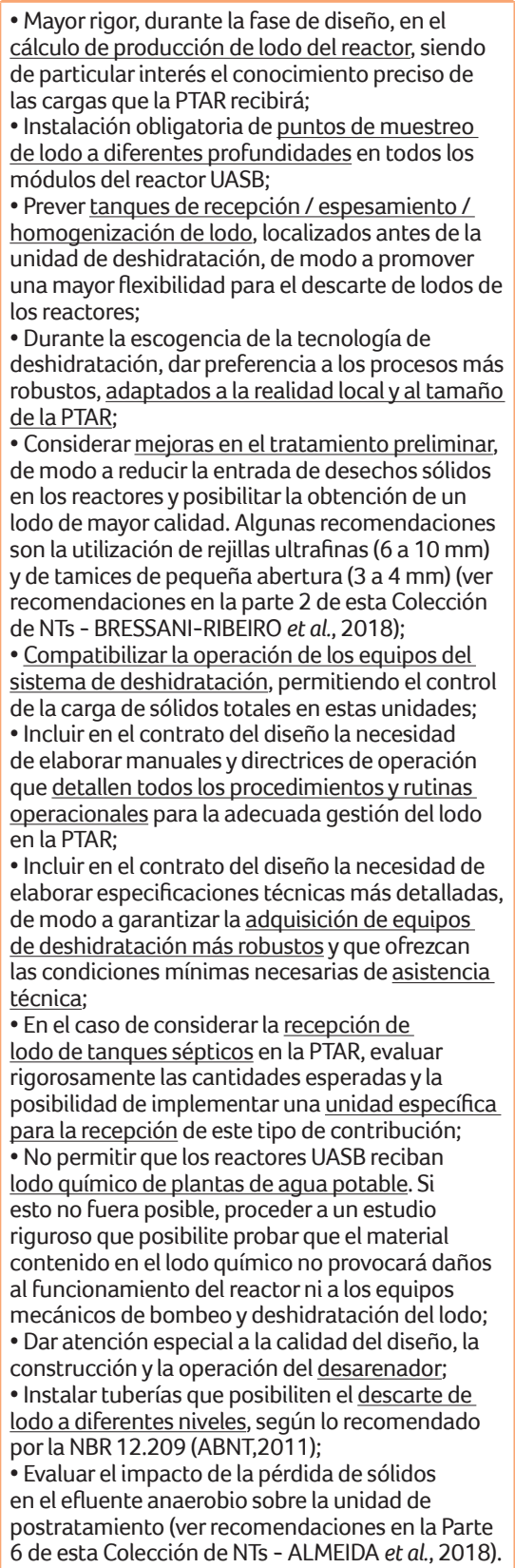 \\
\hline
\end{tabular}




\begin{tabular}{|c|c|c|c|}
\hline Temas de interés & Problemas asociados & Origen del problema & Posibles mejoras \\
\hline $\begin{array}{l}4 \text { - Corrosión y } \\
\text { emisiones odorantes }\end{array}$ & $\begin{array}{l}\text { - Los problemas de olores y corrosión en } \\
\text { las PTARs que utilizan reactores UASB se } \\
\text { encuentran asociados principalmente } \\
\text { al sulfuro de hidrógeno }\left(\mathrm{H}_{2} \mathrm{~S} \text { ) generado }\right. \\
\text { durante el proceso de tratamiento } \\
\text { anaerobio. Una parte del } \mathrm{H}_{2} \mathrm{~S} \text { formado } \\
\text { permanece disuelto en la masa líquida, } \\
\text { mientras que otra parte se desprende } \\
\text { para la atmósfera gaseosa. La mayor } \\
\text { parte del } \mathrm{H}_{2} \mathrm{~S} \text { liberado de la fase líquida } \\
\text { pasa a formar parte del biogás, pero una } \\
\text { parcela importante es emitida de forma } \\
\text { difusa a lo largo del recorrido de la fase } \\
\text { líquida (vertedores, cajas de registro, } \\
\text { distribuidores rotatorios y otros puntos } \\
\text { que causan turbulencia). Adicionalmente, } \\
\text { problemas de olores y de corrosión } \\
\text { pueden ocurrir también en las estaciones } \\
\text { de bombeo de aguas residuales, en las } \\
\text { unidades de tratamiento preliminar, en los } \\
\text { tanques de retorno y almacenamiento de } \\
\text { lodo etc.; } \\
\text { • El } \mathrm{H}_{2} \mathrm{~S} \text { emitido para la atmósfera posee } \\
\text { un olor característico a huevo podrido } \\
\text { y es perceptible para el olfato humano } \\
\text { en bajísimas concentraciones } ~ \\
\text { ppb), pudiendo causar impactos sobre el } \\
\text { bienestar de la población que vive en las } \\
\text { cercanías de la PTAR. En concentraciones } \\
\text { más elevadas, puede causar riesgos a la } \\
\text { salud de los trabajadores de la PTAR; } \\
\text { • El } \mathrm{H}_{2} \mathrm{~S} \text { emitido para la atmósfera puede } \\
\text { producir severos problemas de corrosión } \\
\text { en las estructuras de concreto reforzado } \\
\text { y en materiales y equipos compuestos } \\
\text { de acero al carbono y hierro fundido. } \\
\text { Ejemplos de materiales y estructuras } \\
\text { susceptibles a presentar corrosión son: } \\
\text { cajas de registro, paredes, losas y tapas de } \\
\text { inspección localizadas en la parte superior } \\
\text { de los reactores; escaleras, pasarelas, } \\
\text { barandas, barreras metálicas y tuberías en } \\
\text { general; materiales y equipos utilizados en } \\
\text { la línea de colecta y transporte de biogás. }\end{array}$ & $\begin{array}{l}\text { - La generación de } \mathrm{H}_{2} \mathrm{~S} \text { en los reactores } \\
\text { anaerobios se debe a la presencia de } \\
\text { compuestos de azufre en el agua residual } \\
\text { cruda, los cuales son reducidos a sulfuro por la } \\
\text { acción de bacterias reductoras de sulfato; } \\
\text { - Las emisiones de } \mathrm{H}_{2} \mathrm{~S} \text { desde la fase líquida } \\
\text { pueden ocurrir tanto de forma puntual (en el } \\
\text { interior del separador trifásico, convirtiéndose } \\
\text { en uno de los compuestos del biogás), como } \\
\text { de forma difusa (a lo largo de recorrido del } \\
\text { efluente líquido). De esta forma, el origen } \\
\text { de los problemas de olory corrosión puede } \\
\text { estar relacionado tanto a la línea de colecta y } \\
\text { tratamiento de biogás, como a las emisiones } \\
\text { difusas a partir de la fase líquida; } \\
\text { - El } \mathrm{H}_{2} \mathrm{~S} \text { que se desprende desde la fase } \\
\text { líquida hacia la fase gaseosa puede promover } \\
\text { la formación de ácido sulfúrico y detonar } \\
\text { el proceso de corrosión. De esta forma, la } \\
\text { existencia de vertedores, cajas de registroy } \\
\text { otros puntos que causen turbulencia en la } \\
\text { masa líquida favorecen la liberación de } \mathrm{H}_{2} \mathrm{~S} \\
\text { y la corrosión de las estructuras de concreto } \\
\text { y metálicas en las inmediaciones de esos } \\
\text { puntos de liberación; } \\
\text { - De esta forma, el origen del problema se } \\
\text { relaciona a cinco factores principales: i) } \\
\text { presencia de compuestos de azufre en el agua } \\
\text { residual cruda afluente al reactor anaerobio; } \\
\text { ii) existencia de singularidades que causan } \\
\text { turbulencia a lo largo del perfil hidráulico } \\
\text { de la PTARy posibilitan la liberación del } \mathrm{H}_{2} \mathrm{~S} \\
\text { disuelto en la fase líquida; iii) utilización de } \\
\text { materiales y revestimientos no resistentes } \\
\text { a la corrosión; iv) baja estanqueidad de la } \\
\text { cámara de gas y manejo inadecuado de las } \\
\text { tapas de inspección de los reactores; y v) baja } \\
\text { eficiencia de combustión en algunos tipos de } \\
\text { quemadores de biogás. }\end{array}$ & 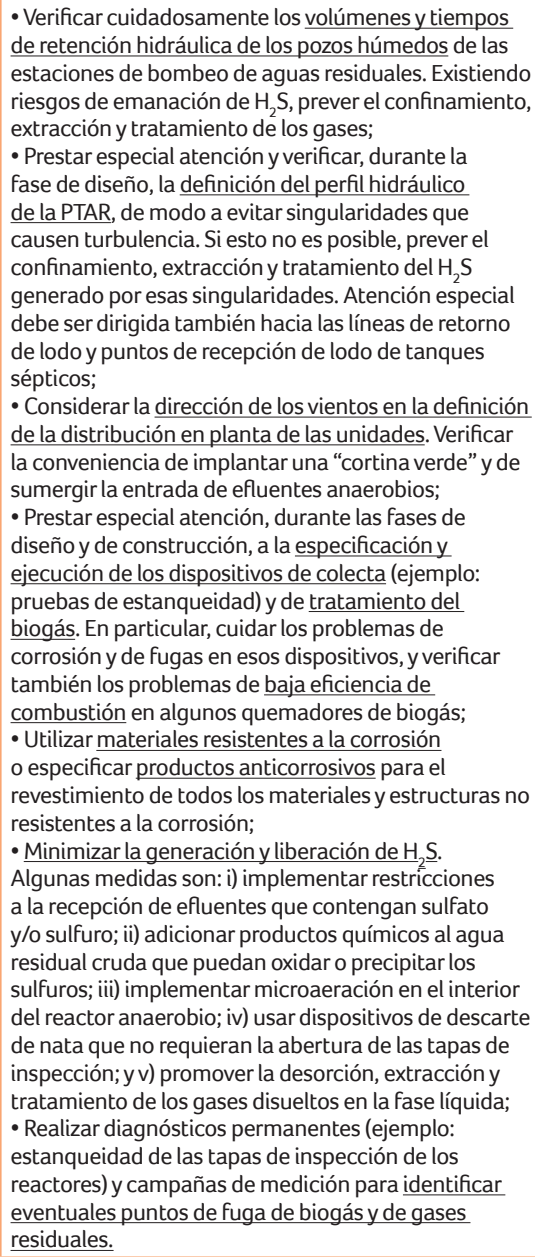 \\
\hline
\end{tabular}




\begin{tabular}{|c|c|c|c|}
\hline Temas de interés & Problemas asociados & Origen del problema & \\
\hline \multirow{4}{*}{$\begin{array}{l}5 \text { - Biogás y emisiones } \\
\text { fugitivas de metano }\end{array}$} & $\begin{array}{l}\text { - Emisión de gases odorantes (sulfuro de } \\
\text { hidrógeno). }\end{array}$ & $\begin{array}{l}\text { - Según lo presentado en el inciso anterior } \\
\text { (4-Corrosión y emisiones odorantes), una } \\
\text { fracción de las emisiones de } \mathrm{H}_{2} \mathrm{~S} \text { desde la } \\
\text { fase líquida son puntuales y pasan a formar } \\
\text { parte del biogás producido en los reactores. } \\
\text { Problemas de estanqueidad en las cámaras } \\
\text { y líneas de gas, la ineficiencia del separador } \\
\text { trifásico y la baja eficiencia en los quemadores } \\
\text { de biogás son las causas de las emisiones } \\
\text { puntuales de gases odorantes. }\end{array}$ & \multirow{4}{*}{ 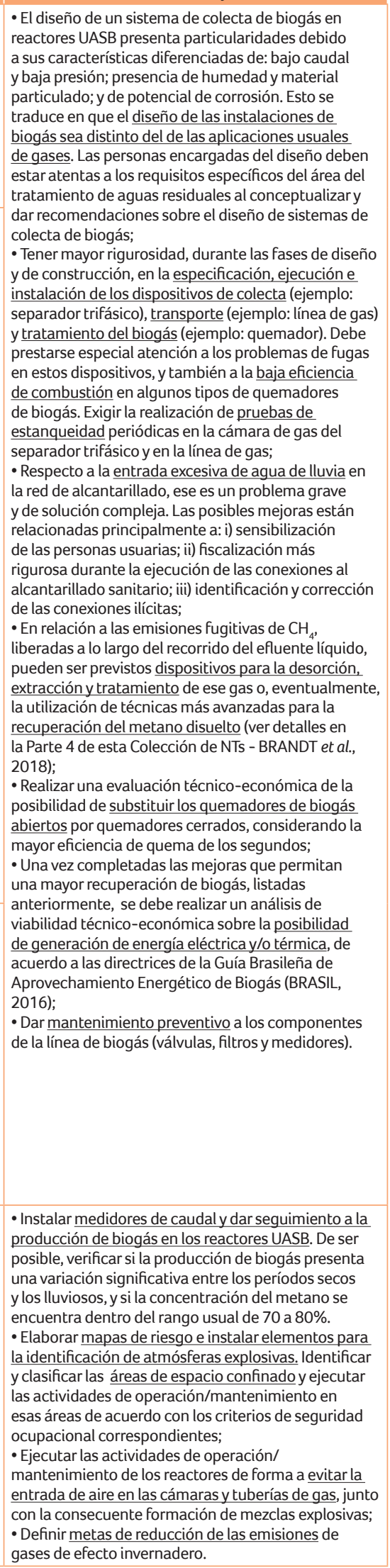 } \\
\hline & $\begin{array}{l}\text { - Emisión de gases de efecto invernadero } \\
\text { (metano). }\end{array}$ & $\begin{array}{l}\text { - El metano }\left(\mathrm{CH}_{4}\right) \text {, producido a partir de } \\
\text { la degradación anaerobia de materia } \\
\text { orgánica, es un gas inodoro y con } \\
\text { elevado poder calorífico (aprovechable } \\
\text { energéticamente) y al mismo tiempo con } \\
\text { elevado potencial de efecto invernadero; } \\
\text { - La mayor parte del metano formado en } \\
\text { los reactores anaerobios es colectada } \\
\text { como biogás, siendo aprovechable } \\
\text { energéticamente. Sin embargo, una } \\
\text { parcela significativa del metano formado } \\
\text { (30 a } 40 \% \text { se disuelve en el medio líquido } \\
\text { y se desprende hacia la atmósfera de } \\
\text { forma dispersa. Esa corriente gaseosa } \\
\text { se conoce como emisiones fugitivas. } \\
\text { Adicionalmente, pueden existir pérdidas } \\
\text { de metano a lo largo de todo el sistema de } \\
\text { colecta, transporte y quema del biogás. } \\
\text { De esta forma, las emisiones de metano } \\
\text { más significativas en reactores UASB se } \\
\text { encuentran normalmente asociadas a: i) } \\
\text { emisiones fugitivas de la parcela que se } \\
\text { encuentra disuelta en el efluente y ii) fugas } \\
\text { en los separadores trifásicos y/o en la línea } \\
\text { de biogás, y/o combustión incompleta en } \\
\text { los quemadores; } \\
\text { - Diseño, materiales y/o instalación } \\
\text { ineficientes de sistemas de remoción o de } \\
\text { rompimiento de nata, que pueden volverse } \\
\text { puntos vulnerables para emisiones } \\
\text { fugitivas de biogás; } \\
\text { - Diseños antiguos o inadecuados que } \\
\text { obviaron la gestión de la fase gaseosa } \\
\text { inherente al tratamiento de aguas } \\
\text { residuales urbanas en reactores UASB. }\end{array}$ & \\
\hline & $\begin{array}{l}\text { - Bajo potencial de aprovechamiento } \\
\text { energético en los reactores anaerobios. }\end{array}$ & $\begin{array}{l}\text { - Elevados niveles de fugas en las cámaras de } \\
\text { gas de los separadores trifásicos y en la línea } \\
\text { de gas son usualmente las principales causas } \\
\text { de las elevadas pérdidas de biogás en los } \\
\text { reactores UASB; } \\
\text { - Entrada excesiva del agua de lluvia en la } \\
\text { red de alcantarillado sanitario durante los } \\
\text { períodos lluviosos, lo que puede ocasionar } \\
\text { una importante dilución del agua residual, } \\
\text { causando una reducción de la producción de } \\
\text { biogás. Adicionalmente, el exceso de caudal } \\
\text { puede provocar sobrecarga hidráulica en el } \\
\text { reactor, generando una pérdida de biomasa } \\
\text { y consecuente pérdida de eficiencia en la } \\
\text { generación de biogás. }\end{array}$ & \\
\hline & $\begin{array}{l}\text { - Aspectos de seguridad vinculados a } \\
\text { la creación de espacios confinados e } \\
\text { identificación y delimitación de espacios con } \\
\text { atmósferas explosivas. }\end{array}$ & $\begin{array}{l}\text { - El biogás se compone mayoritariamente por } \\
\text { metano, un gas inflamable que, mezclado con } \\
\text { oxígeno, puede generar una mezcla explosiva. } \\
\text { Además de eso, en ambientes confinados, } \\
\text { las concentraciones de algunas sustancias } \\
\text { presentes en el biogás (ejemplo: } \mathrm{H}_{2} \mathrm{~S} \text { ) pueden } \\
\text { encontrarse en concentraciones superiores a } \\
\text { los límites de toxicidad para seres humanos. }\end{array}$ & \\
\hline
\end{tabular}




\begin{tabular}{|c|c|c|c|}
\hline Temas de interés & Problemas asociados & Origen del problema & Posibles mejoras \\
\hline \multirow{3}{*}{$\begin{array}{l}6 \text { - Calidad del } \\
\text { efluente }\end{array}$} & - Pérdida de sólidos en el efluente. & $\begin{array}{l}\text { - Lechos de secado y/o equipos de } \\
\text { deshidratación de lodo con fallas de } \\
\text { instalación, con capacidad por debajo de } \\
\text { la necesidad de procesamiento de lodo o } \\
\text { inclusive fuera de operación; } \\
\text { - Falta de protocolos o protocolos } \\
\text { inadecuados para el descarte de lodo en } \\
\text { exceso de los reactores UASB, conforme se } \\
\text { describió en el inciso anterior ( } 3 \text { - Gestión } \\
\text { del lodo); } \\
\text { - Dificultades para implantar rutinas } \\
\text { adecuadas de retorno de lodo aerobio para } \\
\text { espesamiento y digestión en el reactor } \\
\text { UASB; } \\
\text { - Fuga de gases desde el interior del STF } \\
\text { hacia el compartimiento de sedimentación } \\
\text { del reactor UASB, ocasionando arrastre de } \\
\text { sólidos; } \\
\text { - Vertedores desnivelados / obstruidos } \\
\text { causando zonas de sobrecarga hidráulica y } \\
\text { arrastre de sólidos; } \\
\text { - Recepción de efluentes no domésticos; } \\
\text { - Sobrecarga hidráulica y velocidades } \\
\text { ascensionales elevadas asociadas a la } \\
\text { entrada excesiva de agua pluvial en la red } \\
\text { de alcantarillado sanitario; } \\
\text { - Picos de caudal excesivos y velocidades } \\
\text { ascensionales elevadas debido a } \\
\text { estaciones de bombeo mal dimensionadas } \\
\text { o que operan con apenas una bomba y que } \\
\text { no disponen de variadores de frecuencia, } \\
\text { así como consideraciones de diseño } \\
\text { inadecuadas en relación a la estimación } \\
\text { del caudal máximo (de pico). }\end{array}$ & $\begin{array}{l}\text { - Instalar obligatoriamente puntos de muestreo } \\
\text { de lodo a diferentes profundidades en todos los } \\
\text { módulos del reactor UASB; } \\
\text { - Enfatizary detallar en los manuales o directrices } \\
\text { de operación todos los procedimientos y rutinas } \\
\text { operacionales para la adecuada gestión del lodo } \\
\text { en la PTAR, contemplando el retorno de lodo } \\
\text { aerobio, cuando sea necesario; } \\
\text { - Definir una rutina periódica para la verificación } \\
\text { de la nivelación de los vertedores y para detectar } \\
\text { fugas de gases desde el separador trifásico hacia } \\
\text { el compartimiento de sedimentación de los } \\
\text { reactores UASB; } \\
\text { - Con respecto a la entrada excesiva de agua } \\
\text { pluvial en la red de alcantarillado sanitario, las } \\
\text { posibles mejoras fueron indicadas en el inciso } \\
\text { anterior (5- Biogás y emisiones fugitivas de } \\
\text { metano); } \\
\text { - Utilizar bombas con variadores de velocidad } \\
\text { (variadores de frecuencia) o un mínimo de tres } \\
\text { bombas, siendo una de relevo y respaldo, tal como } \\
\text { se recomienda en el inciso } 6.4 .2 \text { de la NBR } 12.209 \\
\text { (ABNT, 2011); } \\
\text { - Controlar la recepción de efluentes no } \\
\text { domésticos (END). }\end{array}$ \\
\hline & $\begin{array}{l}\text { - Incumplimiento de los límites de calidad } \\
\text { de vertido. }\end{array}$ & $\begin{array}{l}\text { - El proceso anaerobio tiene limitaciones } \\
\text { intrínsecas asociadas a la eficiencia } \\
\text { de remoción de materia orgánica, } \\
\text { nutrientes y otros compuestos de menor } \\
\text { biodegradabilidad, como por ejemplo los } \\
\text { surfactantes. Sin embargo, dependiendo } \\
\text { de la capacidad de autodepuración } \\
\text { del cuerpo receptor, una única etapa } \\
\text { anaerobia puede ser suficiente para } \\
\text { cumplir con los objetivos de calidad del } \\
\text { cuerpo hídrico. }\end{array}$ & $\begin{array}{l}\text { - La combinación en serie de procesos anaerobios } \\
\text { y aerobios (ejemplo: UASB/Filtro Biológico } \\
\text { Percolador) tiende a aprovechar de la mejor } \\
\text { manera las ventajas individuales de cada sistema. } \\
\text { La remoción de surfactantes y } \mathrm{N} \text {-amoniacal puede } \\
\text { ser sistemáticamente obtenida en sistemas de } \\
\text { postratamiento compuestos por lodos activados, } \\
\text { filtros aerobios sumergidos, wetlands, lagunas de } \\
\text { pulimento y filtros biológicos percoladores; } \\
\text { - La utilización de sistemas de postratamiento } \\
\text { asociados a la aplicación en el suelo y al reuso } \\
\text { del efluente para fines con requisitos de } \\
\text { calidad del efluente menos exigentes (ejemplo: } \\
\text { humedecimiento del suelo para reducir el polvo) } \\
\text { puede disminuir la necesidad de remoción de } \\
\text { nutrientes; } \\
\text { - La precipitación físico-química de fósforo puede } \\
\text { ser una alternativa cuando la remoción de ese } \\
\text { elemento sea necesaria; } \\
\text { - Buscar alternativas de uso del efluente, inclusive } \\
\text { en las propias instalaciones de la PTAR (ejemplo: } \\
\text { preparación de soluciones de polímero e irrigación } \\
\text { de jardines). }\end{array}$ \\
\hline & $\begin{array}{l}\text { - Deficiencias de la unidad de } \\
\text { postratamiento. }\end{array}$ & $\begin{array}{l}\text { - La pérdida de sólidos en los reactores } \\
\text { UASB puede resultar en sobrecargas en las } \\
\text { unidades de postratamiento, pues tiende } \\
\text { a perjudicar los procesos de transferencia } \\
\text { de masa, consumo de oxígeno y remoción } \\
\text { de contaminantes, contribuyendo } \\
\text { también para la colmatación de sistemas } \\
\text { de biomasa adherida (que utilizan algún } \\
\text { medio de soporte); } \\
\text { - El problema de colmatación tiende a } \\
\text { agravarse en el caso de Filtros Biológicos } \\
\text { Percoladores rellenos con piedra, } \\
\text { principalmente cuando hay ausencia } \\
\text { de una especificación adecuada para la } \\
\text { granulometría durante la fase de diseño, } \\
\text { o cuando hay fallas de inspección y } \\
\text { fiscalización durante la etapa constructiva. }\end{array}$ & $\begin{array}{l}\text {-Evaluar el impacto de la pérdida de sólidos } \\
\text { en el efluente anaerobio sobre la unidad de } \\
\text { postratamiento; } \\
\text { - Mayor rigor durante la fase de diseño con } \\
\text { respecto a la especificación del material de relleno } \\
\text { para sistemas de postratamiento de biomasa } \\
\text { adherida; } \\
\text { - Rigurosidad del equipo de inspección durante el } \\
\text { seguimiento de la obra. }\end{array}$ \\
\hline
\end{tabular}




\section{CONSIDERACIONES FINALES}

Según lo expuesto en esta Nota Técnica, los problemas relacionados con el tratamiento de aguas residuales urbanas por reactores UASB pueden estar asociados a deficiencias de diseño, de construcción y de operación. Además, la ineficiencia de mecanismos de administración impide/dificulta el cumplimiento de procedimientos adecuados de contratación de proyectos, servicios tercerizados, compra de equipos, fiscalización de obras y disponibilización de recursos humanos calificados para la correcta operación de los sistemas de tratamiento de aguas residuales. Se aclara que estos problemas de administración ocurren en la mayoría de las PTARs, independientemente de la tecnología de tratamiento utilizada.

Con esta Colección de Notas Técnicas, se espera contribuir para un mejor entendimiento de los diferentes problemas y de sus orígenes, así como para el señalamiento de las mejoras necesarias de diseño, construcción y operación de reactores anaerobios aplicados al tratamiento de aguas residuales urbanas. Aunque son muchos los problemas detectados, la gran mayoría puede ser corregida de manera simple y efectiva, sin impactos significativos para el costo de los reactores.

En ese sentido, se incentiva a las personas encargadas de la administración, consultoría, diseño, construcción y operación de sistemas de tratamiento de aguas residuales urbanas basados en reactores UASB a que se actualicen y profundicen sus conocimientos sobre los temas de interés discutidos en esta Nota Técnica, los cuales son detallados en las otras cinco Notas Técnicas (Partes 2 a 6) que integran esta Colección.

\section{AGRADECIMIENTOS}

Los autores agradecen a la estudiante de ingeniería civil de la Universidad Federal de Minas Gerais (UFMG), Vanessa Rodrigues de Melo. A los ingenieros de la Sabesp, Bruno Sidnei da Silva y Luiz Yoshiharu Ito, por las contribuciones a lo largo de la elaboración de esta Nota Técnica. Se agradece igualmente el apoyo recibido del Consejo Nacional de Desarrollo Científico y Tecnológico - CNPq (Conselho Nacional de Desenvolvimento Científico e Tecnológico), de la Coordinación de Mejoramiento de Personal de Nivel Superior - CAPES (Coordenação de Aperfeiçoamento de Pessoal de Nível Superior), de la Fundación de Amparo a la Investigación del Estado de Minas Gerais - FAPEMIG (Fundação de Amparo à Pesquisa do Estado de Minas Gerais) y del Instituto Nacional de Ciencia y Tecnología en Plantas Sostenibles de Tratamiento de Aguas Residuales Urbanas (INCT ETEs Sustentáveis por sus siglas en portugués).

Este trabajo forma parte de la serie de publicaciones del Instituto Nacional de Ciencia y Tecnología en Plantas Sostenibles de Tratamiento de Aguas Residuales Urbanas (INCT ETEs Sustentáveis por sus siglas en portugués).

\section{REFERENCIAS BIBLIOGRÁFICAS}

ALEM SOBRINHO P., JORDÃO E.P. Pós-tratamento de efluentes de reatores anaeróbios - uma análise crítica. Capítulo. 9. In: CHERNICHARO, C.A.L. (coordinador). Pós-tratamento de efluentes de reatores anaeróbios. FINEP/PROSAB, Rio de Janeiro, 544 p., 2001.

ALMEIDA, P.G.S., BRESSANI-RIBEIRO, T.B., SILVA, B.S., AZEVEDO, L. S., CHERNICHARO, C.A.L. Contribución para el perfeccionamiento del diseño, la construcción y la operación de reactores UASB aplicados al tratamiento de aguas residuales urbanas - Parte 6: Calidad del efluente. Revista DAE - edición especial, v. 66, n. 214, p. 90-108, 2018.

BRANDT, E. M. F., SANTOS, J. M. B., SOUZA, C. L., POSSETTI, G. R. C., BRESSANI- RIBEIRO, T. B., CARVALHO-JÚNIOR, A. N., CHERNICHARO, C. A. Contribución para el perfeccionamiento del diseño, la construcción y la operación de reactores UASB aplicados al tratamiento de aguas residuales urbanas - Parte 4: Control de corrosión y emisiones odorantes. Revista DAE - edición especial, v. 66 , n. 214, p. 56-72, 2018.

BRASIL - Secretaria Nacional de Saneamento Ambiental do Ministério das Cidades/Probiogás. Resultados do projeto de medições de biogás em reatores anaeróbios. Brasília, Distrito Federal: Ministério das Cidades, 2017. 128 p.

BRESSANI-RIBEIRO T., LOBATO, L. C. S., SOUZA, S. N., PEGORINI, E. S., CHERNICHARO, C. A. L. Contribución para el perfeccionamiento del diseño, la construcción y la operación de reactores UASB 
aplicados al tratamiento de aguas residuales urbanas - Parte 2: Tratamiento Preliminar. Revista DAE - edición especial, v. 66, n. 214, p. 17-29, 2018.

CAMPOS, J. R. (coordenador). Tratamento de esgotos sanitários por processo anaeróbio e disposição controlada no solo. São Carlos: reatores anaeróbios. Belo Horizonte: FINEP, 464 p., 1999.

CHERNICHARO, C. A. L. (coordinador). Pós-tratamento de efluentes de reatores anaeróbios. Belo Horizonte: FINEP/PROSAB Programa de Pesquisa em Saneamento Básico, 544 p., 2001.

CHERNICHARO, C. A. L. Post-Treatment Options for the Anaerobic Treatment of Domestic Wastewater. Reviews in Environmental Science and Bio/Technology, v. 5, n. 1, p. 73-92, 2006.

CHERNICHARO, C. A. L., VAN LIER, J.B., NOYOLA, A., BRESSANI-RIBEIRO, T. Anaerobic sewage treatment: state of the art, constraints and challenges. Reviews in Environmental Science and Bio/Technology. v. 14, n. 4, p. 649-679, 2015.

CHERNICHARO, C.A.L., BRESSANI-RIBEIRO, T., GARCIA, G.B., LERMONTOV, A., PEREIRA, C.B., PLATZER, C.J., POSSETTI, G.R.C., LEITES, M.A.L., ROSSETO, R., 2018. Panorama do tratamento de esgoto sanitário nas regiões Sul, Sudeste e Centro-Oeste do Brasil: tecnologias mais empregadas. Revista DAE, v. 66, n. 213, p.5$19,2018$.

LETTINGA G. My Anaerobic Sustainability Story, Lettinga Foundation, 2014

LOBATO, L. C. S., BRESSANI-RIBEIRO, T., SILVA, B. S., FLÓREZ, C. A. D., NEVES, P. N. P., CHERNICHARO, C. A. L. Contribución para el perfeccionamiento del diseño, la construcción y la operación de reactores UASB aplicados al tratamiento de aguas residuales urbanas - Parte 3: Gestión del lodo y la nata. Revista DAE - edición especial, v. 66, n. 214, p. 30-55, 2018.

MIKI, M.K. Dilemas do UASB. Revista DAE, v. 183, n.1504, p. 25-37, 2010.

MORAN, M. J., SHAPIRO, H. N., BOETTNER, D.D., BAILEY M.B. Fundamentals of Engineering Thermodynamics. 7th edición.: John Wiley \& Sons. 2010

POSSETTI, G. R. C., RIETOW, J. C., COSTA, F. J. O. G., WAGNER, L. G., LOBATO, L.C.S., BRESSANI-RIBEIRO, T., MELO, D. F., REIS, J.A., CHERNICHARO, C. A. L. Contribución para el perfeccionamiento del diseño, la construcción y la operación de reactores UASB aplicados al tratamiento de aguas residuales urbanas - Parte 5: Biogás y emisiones fugitivas de metano. Revista DAE - edición especial, v. 66, n. 214, p. 73-89, 2018.

SILVA, S. M. C. P. Desenvolvimento de uma nova concepção de tratamento de águas residuárias pela associação de processos anaeróbios e aeróbios. Tesis (Doctorado). Escuela Politécnica de la Universidad de São Paulo. São Paulo, 1993.

von SPERLING, M., CHERNICHARO, C.A.L. Biological Wastewater Treatment in Warm Climate Regions. IWA Publishing, London, 1452 p., 2005.

YOUNG, J.C., MCCARTY, P.L. The anaerobic filter for waste treatment. Journal (Water Pollution Control Federation), v.5.1. p. 160-173, 1969. 